\title{
Assessing environmental impacts through innovative solutions
}

\author{
Evangelia E. Golia ${ }^{1,2} \cdot$ Antonis Zorpas ${ }^{3}$
}

Published online: 10 February 2022

(c) The Author(s), under exclusive licence to Springer-Verlag GmbH Germany, part of Springer Nature 2022, corrected publication 2022

The present editorial introduces to a special issue in Environmental Science and Pollution Research journal, focusing upon selected papers presented at the Sixth International Symposium on Green Chemistry, Sustainable Development and Circular Economy that took place in Thessaloniki, Greece, in September 2020 (GreenChem6).

The main symposium goal was to bring scientists, professionals, and researchers from various areas together, to present and discuss topics related to Green Chemistry, sustainable development, and circular economy for a better environment and a healthier life. Considering the transition to circular economy, the European Green Deal strategy as well as the 17 SDG that UN has announced, innovative solutions on proposed strategies are imperative. Environmental impact can be estimated through evidence and should not be made on assumptions, and these need to be based on a robust understanding of the socio-economic effects of public and industrial intervention. Innovation is expected to diminish amounts of waste, air pollution, and material resource exhaustion and to increase the reuse of other materials, in order to facilitate in the successful transition to circular economy.

Responsible Editor: Philippe Garrigues

Evangelia E. Golia

egolia@agro.auth.gr

Antonis Zorpas

antonis.zorpas@ouc.ac.cy; antoniszorpas@yahoo.com

1 Laboratory of Soil Science, School of Agriculture, Aristotle University of Thessaloniki, University Campus, 54124 Thessaloniki, Greece

2 Laboratory of Soil Science, Department of Agriculture, Crop Production and Agricultural Environment, University of Thessaly, 38446 Volos, Greece

3 Laboratory of Chemical Engineering and Engineering Sustainability, Faculty of Pure and Applied Sciences, Open University of Cyprus, Giannou Kranidioti 33, 2220 Latsia, Nicosia, Cyprus
Research and innovation policy supports a range of research activities to offer direct and indirect provisions to technology diffusion. Limited consideration of the environment or creation of negative environmental impacts jeopardizes the entire sustainability level. When the system underperforms and the innovation potential cannot counterbalance environmental deterioration, then the long-term sustainability also fails. This is what Green Chemistry solutions strive to avoid.

As such, scientists, researchers, professionals, environmentalists, and policy makers had the opportunity to present their valuable input to the related conference. They were also able to discuss current issues related to environmental toxicity, risk assessment, environmental protection, and conservation.

The 12 selected articles embody the purposes of the scientific approach of the conference and are briefly discussed here.

The importance of maintaining the marine environment in a healthy state is self-evident. The research carried out by Squadrone et al. (2021) shows that the microplastics can be vectors of metal ions leading to contamination in Mediterranean Sea. It is well known that microplastics are contaminants of great environmental concern as they can increase the enrichment capability of other pollutants, causing their entry in the marine food web.

The heterotrophic cultivation of Chlorella vulgaris grown with glycerol was investigated by Gougoulias et al. (2021). The investigation of the kinetics of the heterotrophic growth of Chlorella vulgaris as a means of producing bio-oil for biodiesel is the main aim of the research. Anaerobic digestion was found to be of potential use in the formulation of bioreactor culture media, reducing the use of potassium, phosphorus, and micronutrients from natural resources.

Furthermore, Meng et al. (2021) created an evolutionary game theory-based analysis for the dynamic reward and penalty strategies of green building construction incentive. It is stressed therein that the contractors should actively introduce 
and learn new construction technology, adopt reasonable green technology in combination with local conditions, and comprehensively consider adaptability and economy.

$\mathrm{Li}$ et al. (2021) investigated how environmental values impact green product purchase intention regarding green trust. The results revealed that, when green trust was high, environmental concern enhanced the promotion effect of green product purchase intention. It is imperative to establish consumers' green trust in green marketing, as such enterprises should further enhance their certification systems of environmental labels and green products, standardize the certification systems, and strictly control the issuance of green certification marks.

Golia and Diakoloukas (2021) used a robust quadratic regression approach of soil pollution prediction after a 5-year-long field research. They investigated the soil parameters that affect the levels of potentially harmful metals (PHM) in Thessaly area, Greece. Soil reaction, electrical conductivity, organic matter, clay and sand content, exchangeable cations, and metals oxides have been assumed to influence the pseudo-total concentrations of metals in soils of different soil orders. Based on new data collections in the future, the proposed prediction equations could be verified, further optimized, and proved to be accurate enough to serve as a useful tool for PHM's contamination monitoring.

Conversion of brewers' spent grain (BSG) into proteinaceous animal feed using solid state fermentation had been investigated by Eliopoulos et al. (2021). The study highlighted the grain's potential for augmented commercial price which is in the line/related with the protein's content increase achieved by solid state fermentation bioprocess. Thus, the BSG is strongly recommended for animal nutrition for its physicochemical properties as well as for reducing its environmental impact in the context of the circular economy.

Fluopyram removal from rinsing water of agricultural equipment with the use of horizontal subsurface flow pilotscale constructed wetlands was investigated by Parlakidis et al. (2021). Five pilot-scale constructed wetlands, with different characteristics, were employed in the removal of fluopyram from aqueous solution. Based on the findings of the present study, fluopyram removal was mainly achieved through microbial biodegradation, adsorption on porous media, and bioaccumulation processes. Furthermore, the addition of zeolite as a substrate material caused an enormous increase of fluopyram absorption on porous media.

Charitopoulou et al. (2021) studied the effect of brominated flame retardant on the pyrolysis products of polymers originating in waste of electric and electronic equipment (WEEE). During the solvent casting method, there were obtained two peaks giving a chlorinated compound (2-chlorobiphenyl), due to incomplete evaporation of chlorobenzene (solvent) during the preparation. According to this observation, the melt-mixing method (in an extruder) may be considered a more advantageous method than the solvent casting, considering that during the former method pyrolysis, products were not affected.

Mavriou et al. (2021) investigated the bioprocess performance, along with the transformation pathway, and the bacterial community dynamics in an immobilized cell bioreactor treating fludioxonil-contaminated wastewater under microaerophilic conditions. The developed immobilized cell bioreactor operating under microaerophilic conditions was proven to be an efficient and cost-effective method for the depuration of fungicide-rich wastewaters generated by the fruit packaging industry.

The production of hydroxytyrosol-rich extract from Olea europaea leaf with enhanced biological activity using immobilized enzyme reactors was investigated by Chatzikonstantinou et al. (2021). The proposed bioprocess was economically viable as it employs low-priced enzyme and immobilization matrices while at the same time it demonstrated good productivity. Finally, the proposed process could also be applied for the valorization of olive mill wastewaters, which are also rich in oleuropein and other phenolic compounds that could be exploited by the pharmaceutical and food industry.

Zhao et al. (2021) studied the fabrication of a novel bio-adsorbent (alginate-based composite beads) and its application for the removal of $\mathrm{Cu}$ (II) from aqueous solution. The stable surface structure of the adsorbent was confirmed by further characterization analysis. The adsorption performance was evaluated by using batch adsorption experiment, and the maximum adsorption capacity of the beads for $\mathrm{Cu}$ (II) was calculated by Langmuir model. The adsorption kinetics studies showed that the adsorption process for $\mathrm{Cu}$ (II) was mainly controlled by chemical adsorption, and Langmuir model indeed fitted the adsorption parameter.

Zhang et al. (2022) investigation was concerning the degradation of oxytetracycline by a magnetic MOFs heterojunction photocatalyst with persulfate. The magnetic type was accomplished by a hydrothermal method, which demonstrated excellent degradation performance against the antibiotic in the presence of coupled persulfate. The $\mathrm{Fe}_{3} \mathrm{O}_{4} / \mathrm{MIL}-101$ photocatalyst coupled with persulfate is an effective method for the degradation of organic pollutants in water bodies.

The above-mentioned scientific papers mirror the broad and multidisciplinary research presented and promoted in GreenChem6. This joint effort came into fruition due to the dedication and the punctuality of the authors, the professionalism and the commitment of the ESPR journal, and the experience and the enthusiasm of the guest editors. We believe that the journal's distinguished readers will find this special issue of particular interest to them. 


\section{References}

Charitopoulou A, Papadopoulou L, Achilias DS (2021) Effect of brominated flame retardant on the pyrolysis products of polymers originating in WEEE. Environ Sci Pollut Res. https://doi.org/10. 1007/s11356-021-15489-8

Chatzikonstantinou A, Giannakopoulou A, Spyrou S et al (2021) Production of hydroxytyrosol rich extract from Olea europaea leaf with enhanced biological activity using immobilized enzyme reactors. Environ Sci Pollut Res. https://doi.org/10.1007/ s11356-021-17081-6

Eliopoulos C, Arapoglou D, Chorianopoulos N et al (2021) Conversion of brewers' spent grain into proteinaceous animal feed using solid state fermentation. Environ Sci Pollut Res. https://doi.org/ $10.1007 / \mathrm{s} 11356-021-15495-\mathrm{w}$

Golia EE, Diakoloukas V (2021) Soil parameters affecting the levels of potentially harmful metals in Thessaly area, Greece: a robust quadratic regression approach of soil pollution prediction. Environ Sci Pollut Res. https://doi.org/10.1007/s11356-021-14673-0

Gougoulias N, Papapolymerou G, Mpesios A et al (2021) Effect of macronutrients and of anaerobic digestate on the heterotrophic cultivation of Chlorella vulgaris grown with glycerol. Environ Sci Pollut Res. https://doi.org/10.1007/s11356-021-17698-7

Li G, Yang L, Zhang B, Li X, Chen F (2021) How do environmental values impact green product purchase intention? The moderating role of green trust. Environ Sci Pollut Res Int 28(33):46020 46034. https://doi.org/10.1007/s11356-021-13946-y

Mavriou Z, Alexandropoulou I, Melidis P et al (2021) Bioprocess performance, transformation pathway, and bacterial community dynamics in an immobilized cell bioreactor treating fludioxonilcontaminated wastewater under microaerophilic conditions. Environ Sci Pollut Res. https://doi.org/10.1007/s11356-021-16452-3

Meng Q, Liu Y, Li Z, Wu C (2021) Dynamic reward and penalty strategies of green building construction incentive: an evolutionary game theory-based analysis. Environ Sci Pollut Res Int 28(33):44902-44915. https://doi.org/10.1007/ s11356-021-13624-Z

Parlakidis P, Mavropoulos T, Vryzas Z et al (2021) Fluopyram removal from agricultural equipment rinsing water using HSF pilot-scale constructed wetlands. Environ Sci Pollut Res. https://doi.org/10. 1007/s11356-021-15373-5

Squadrone S, Pederiva S, Bezzo T, Sartor RM, Battuello M, Nurra N, Griglione A, Brizio P, Abete MC (2021) Microplastics as vectors of metals contamination in Mediterranean Sea. Environ Sci Pollut Res Int 30. https://doi.org/10.1007/s11356-021-13662-7

Zhang Z, Du C, Zhang Y et al (2022) Degradation of oxytetracycline by magnetic MOFs heterojunction photocatalyst with persulfate: high stability and wide range. Environ Sci Pollut Res. https://doi. org/10.1007/s11356-021-17971-9

Zhao D, Ye W, Cui W (2021) Fabrication of novel bio-adsorbent and its application for the removal of $\mathrm{Cu}$ (II) from aqueous solution. Environ Sci Pollut Res. https://doi.org/10.1007/s11356-021-17013-4

Publisher's note Springer Nature remains neutral with regard to jurisdictional claims in published maps and institutional affiliations.

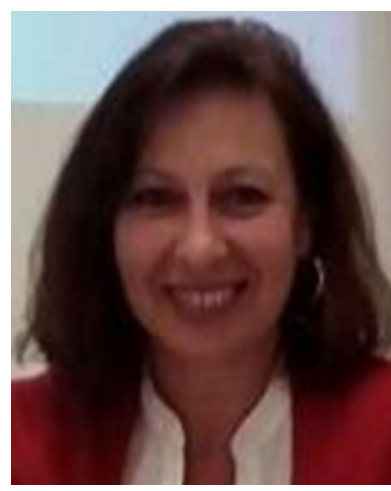

Dr. Evangelia E. Golia , is Associate Professor in the Faculty of Agriculture, Forestry and Natural Environment, School of Agriculture, Department of Hydraulics, Soil Science and Agricultural Engineering, Laboratory of Soil Science in Aristotle University of Thessaloniki (AUTH) and as a visiting Professor in University of Thessaly (UTH), in Cyprus University of Technology (CUT), and in the University of Wuppertal (BERGISCHE UNIVERSITAT WUPPERTAL). She has received her bachelor's degree in Chemistry from Aristotle University of Thessaloniki and a second bachelor's degree in Agriculture, Department of Agriculture Crop Production and Rural Environment in University of Thessaly, Greece. Her Master of Science is in Quality Assurance, Greek Open University, and her PhD is in Soil Science, Department of Agriculture, Crop Production and Rural Environment, University of Thessaly. Her Postdoctoral Research was conducted between the SZENT ISTVAN University, Hungary and the Department of Agriculture Crop Production and Rural Environment, School of Agricultural Sciences, University of Thessaly, Greece. Her research fields are Environmental Analysis (use of atomic absorption spectrophotometer, ICPAES, ionic chromatography), Environmental monitoring using GIS, sample preparation techniques for the analysis of metals, development and validation of analytical methods for determination of metals in environmental and food samples, and physicochemical behavior of metals in environment-transportation of metals and metalloids in environmental compartments. Adsorption-desorption studies. She has published 32 papers in peer-reviewed journals, 55 papers in International Conferences, and 25 papers in Greek Conferences and she has taken part as an investigator in more than 10 projects in AUTH and University of Thessaly.

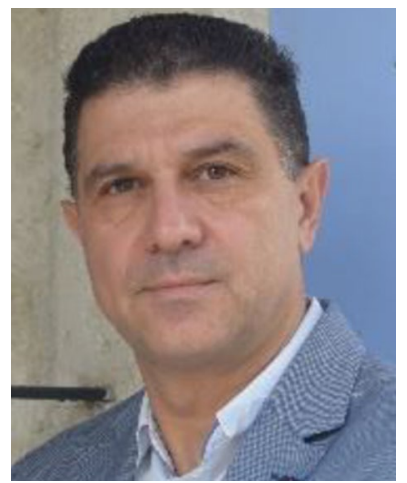

Dr. Antonis Zorpas , is a Chemical Engineer with a $\mathrm{PhD}$ in Environmental Management and Engineering. He is actively engaged with several universities and research institutes in Europe. $\mathrm{He}$ is (at this stage) Associate Professor at Open University of Cyprus (Faculty of Pure and Applied Science and he is the Director of the Lab of Chemical Engineering and Engineering Sustainability). He is the Academic coordinator of the Master Program of Environmental Conservation and Management as well as for the new upcoming Master Program in Sustainable Environmental Engineering. He has more than 450 publications (including editor in scientific books, contribution on books, papers in scientific journals and international conferences, and with google h-index $>35$ ). For more than 20 years, he was acting as Consulting Engineer on behalf of several industrial activities, government and local authorities. He was from 2013 to 2019 the President of Cyprus Environmental Engineers Council, his active member of the Scientific Advisory Committee of the Office of the Cyprus Commissioner for the Environment (20132019) as well as was an Elected Member of the Senate of his University the period 2018-2022 and the President of the Research Committee of his University (2019-2022). He was on the Board of experts on the 
EURASHE (European Association of Institutions in Higher Education 2016-2019) Committee in Brussels and his Scientific Cooperator with EU. His research background is in the area of Strategic Panning Development in the Framework of Waste Management, Circular and BioEconomy, Waste Valorization, Waste to energy, European Green Deal, Biosolids treatment and management, hazardous waste treatment, End of Waste Criteria, waste minimization, zero waste approach, waste prevention, social behavior, city metabolism, household and solid waste management, Life Cycle Analysis and Environmental Risk analysis, SDGs, green entrepreneurship etc. He has participated in more than 70 research project the last 15 years. On 2019 has received honorary distinction for his long-standing contribution to the environmental issues of Cyprus from the President of the Republic of Cyprus. Furthermore, his has recognized among the worlds to $2 \%$ in the list of scholars in his field in the study "Updated science-wide author databases of standardized citation indicators, 2020" published recently by a research team of the Stanford University (USA) which include the list of the most influential researchers in the world reflects the excellence of the University's academics and researchers and the quality of their scientific work. His publication record can be found here: (a) https://scholar. google.com/citations?user=D7koX6YAAAAJ\&hl=en. (b) https:// www.researchgate.net/profile/Antonis_Zorpas. (c) https://www.scopus. com/authid/detail.uri?authorId=6603816522. His extended Profile in LinkedIn can be found here: https://www.linkedin.com/in/antonis-zorpas-97b60824/ 